\title{
The Knowledge of Counselors in Balqa Governorate Behavior Modification Strategies in Light of Some of the Variables
}

\author{
D-Nagham Mohammad Abu Al-basel ${ }^{1}$ \\ ${ }^{1}$ Princess Rahma-College, Al-Balqa- Applied University, Alsalt, Jordan \\ Correspondence: D-Nagham Mohammad Abu Al-basel, Princess Rahma-College, Al-Balqa- Applied University, \\ Alsalt, Jordan. E-mail: mohammedolimat29@yahoo.com
}

Received: July 25, 2013

doi:10.5539/ies.v6n9p150
Accepted: August 12, 2013 Online Published: August 29, 2013

URL: http://dx.doi.org/10.5539/ies.v6n9p150

\begin{abstract}
The present study aimed to identify the extent of knowledge of counselor behavior modification strategies. The current study sample consisted of (80) mentor and guide, were selected randomly from among all workers enrolled in regular public schools in the Balqa governorate represented the community study for the academic year 2012-2013.

The study tools consisted of the test include (48) paragraph of multiple choice type in the form of questions in the field of behaviors' modification strategies. The results of study findings with respect to the question nr.1 that there is a high level of knowledge in the behavior modification counselors, the result of the study finding with respect to the question nr.2 to the absence of statistically significant differences for the degree of knowledge strategies to modify the behavior attributed to the sex, the results showed statistically significant differences for the variable years of experience for the benefit of ten years and more.
\end{abstract}

Keywords: behavior modification, Balqa governorate, education, knowledge strategies

\section{Introduction}

Technology has achieved behavior modification in the past four decade tremendous success in the field of education and specifically, only this technology provided affective strategies for therapeutic and educational possible employed successfully and easily to form adoption behavior and the removal of non-adaptive behavior in different age categories and characteristic in conditions that applied miscellaneous (Therapeutic, rehabilitative, educational, extension) has had a successful impact on the path of education regular education in both. (Hursh, Schumaker, Fawcett \& Sherman, 2000).

By reference to the historical perspective, the first use of the term behavior modification was at the hands of the world (Eduardo Thorndike 1911) in his article "temporary laws of behavior syndrome or to learn and then have repeated use of the term behavior modification in the forties and fifties of the last century through empirical research carried out by (Joseph Wolpe 1958) and his team, which came in a study of (Abu Abed and Alhawash of the year 2011) this term had used in the field of clinical psychology to refer to methods of psychotherapy derived from experiment research. Has been used since then mainly-refers to techniques of punishment and its alternatives, (Marlin, Pear 2007)

With regard to establishment of technology to modify the behavior has contributed to theories of learning of which is clearly due this trend to tests conducted by the Russians scientist (Ivan Patrovich Pavlov 1849 - 1936) known as conditional classic as well as to the founder to behaviorism in the twenties of the last century, (John Watson 1878-1958) which focused attention on the study behavior, in the simplest image by conducting experiments on animals (Al-Ayed, 2011).

Behavior modification is a branch of psychology applied and defined as the direct application and orderly methods that emerged from the school behavioral to a fundamental change and is useful in behavior (Abu-Hmeidan,2003), and this is done through the organization of the circumstances and environmental variables present relevant behavior, in particular those which occur after behavior (Martin, 2007).

Behavior modification procedurally known as a set of actions aimed at strengthening behavior adaptive through strategies boosters and alternatives on the one hand, fold or remove behaviors is adaptive through the use of techniques to erase or punishment and its alternatives on the other hand (Spales; Pagoto) (Kalato, 2006) and also 
includes encroachments behavior to provide evidence that these measures alone and non other is that underlie the observed change in behavior, and perhaps the most important characteristic of the behavior focus on the study of behavior stainless note direct and functional analysis of individual interactions with the environment (Khatib, 2003).

On the first principles that he believes theorists to modify the behavior that most behaviors are behavior educated, as well as believe it is possible to modify the behavior or changed by the principles of learning (Alberto \& Troutman, 2000) and therefore we can apply these principles in the field of education in general, and so out from the belief that there are stimuli or keys move the response of the individual towards achieving its objective and if the saturated response or reinforced any awarded reinforcement or reward and good in return. They tend to repetition and return to occur in situation future coming so based on one of educational law which is a law effect, (Malika, 1994).

This sequence is expressed as the law (interestingly, response) if any found exiting it must be produced by the response, and the effecter distinguish between a number of stimuli, as passed by to learn term, these features replaces each other to give same response this phenomenon is known as (Stimulus Generalization) (Martin, Pear, 2007). Thus can be linked any in any response and here lies the role of the counselor in helping students to identify the bad responses so replaces it with other good responses and here this response can be adjusted with another exclusive together, (Malika, 1994).

School behavior based on what called objective study of the behavior, the first objective lies in identifying how to learn abnormal behavior or how it was earned, because the behavioral school believes that abnormal behavioral is the educational behavior and thus similar to other normal behavior (Al-Khatib, 2003).

After passing quickly on behavior modification technology question arises about the importance of knowledge of behavior modification strategies of educational guide, educational guide the expert described as a person he is an experienced and learn more than those experiences and knowledge of learner (Geslo, Samslag, 2008) for above his role based on the cycle therefore interpret the facts and provide guiding information and expansion or narrowing of the fields in front of him making it easier to test for the process of issuing decisions' and determine its position on the events, surrounding it, as well as the wiser leader of the understanding and interpretation of guiding problems and then the guided puts his life history in front of him so that he can guide himself to have a knowledge of his problems, and thus can help him see his way through these problems (Malika, 1994).

The counselor who uses traditional methods of guidance will face inevitably many difficulties, so there are other methods for guidance reinforce methods of guidance traditional and guidance behavior is one of the most prominent methods that you must provide themselves with their advisor to analyze the alternatives available and accessible to the guided into a state of awareness and understanding of the decisions.

It standpoint guidance behavior based its procedures to behavioral theory, the behavioral problems it is only usually educated false or behavior is adaptive learning guided to reduce the concern and tension, and therefore the role of mentor is very similar to what the role of the teacher, idea guidance behavioral based mainly on leaning or re-learning or erase or remove it (Dizdron, 2009).

Despite the deployment of a huge amount of empirical studies that provided scientific evidence and clear and strong on the effectiveness of behavior modification techniques in the formation of adaptive behavior (Whitman et. al, 1983). However, the studies that have tried to stand over the possession of counselors to behavior modification strategies are almost rare, the study came to try to stand on the extent to which owned counselors to modify the behavior strategy in

\section{Previous Studies}

\subsection{Al-Abed Abu-Hawash Study, 2011}

Present study aimed to identify the extend of knowledge of special education teachers and teachers of students ordinary and counselors strategies for behavior modification, the study sample consisted of current (139) teachers were selected randomly from among all teachers enrolled in regular schools public and private in the city of Amman, who estimated (5000) teachers represented educational academic year 2010/2011, study tools consisted of choice included (40) items of the type of multiple choice in the form of questions in the field of behavior modification and reached results of the study with regard to the first question, that there is a low level of knowledge in behavior modification with the special education teachers and ordinary teachers and counselors, as well as the results indicate that there are apparently reflecting the level of knowledge in behavior modification according to the study variable (special education teacher, regular teacher, an educational guide) as for the 
second question, the result was that there are statistically significant differences between the special education teachers (average $=26.27$ ) and ordinary teachers of students (average $=19.21$ ) for counselors and the same time it was no clear and here are differences statistically significant at the level of $(0.05 \geq \alpha)$ in the level of knowledge behavior modification strategies among special education teachers and counselors.

\subsection{Dezdorn Study 2009}

Which aimed to find out how the use of counselors in regular schools in Ireland for plans and programs based on behavior modification and see the effectiveness of these programs where the study reported that there is use of these plans up to $80 \%$ and that these plans were active in the process of extension and ended many of problem behavioral.

\subsection{Shang Study, 2008}

Aimed to find out how principals, ordinary teachers on how to deal with people with special needs, and their ability to deal with behavioral problems with scientific methods based on the principles of behavior modification where the results indicated that principals and teachers were skill low as indicated to the presence of statistically significant differences in behavior modification skills for the benefit of teachers.

Aimed to measure the knowledge of special education teachers and statisticians speech and language methods used with low syndromes kids and compared with modern methods, where the indicated results of the study to a weakness in the level of knowledge respondents modern methods in dealing with low syndromes generally, which requires re-training and better rehabilitation.

\subsection{Urabi Study, 2007}

Aimed to assess the knowledge of low syndromes kids in the Syrian Arab Republic by behavior modification techniques, researcher developed a tool consisted of (44) paragraph to measure three main dimensions' as follows:General foundations of knowledge to modify behavior and knowledge in ways that strengthen the desired behavior, and knowledge in ways that reduce unwanted behavior.

The results indicated that the average scores of these teachers on the scale as a whole as very close to the value specified by the standard of the jury. Which represents the minimum knowledge of the methods of behavior modification which show they have the minimum of that knowledge in general, the results also show the presence of statistically significant differences in teachers knowledge of the methods of behavior modification in generally attributed to gender in favor of male teachers.

\subsection{Al-Khatib Study, 2005}

The purpose of the statement of effeteness' after a training program collectively to improve the level of knowledge of teachers of children with disabilities skills, behavior modification and the study sample consisted of (41) teachers working in special education centre in the countries of the Gulf Cooperation Council, and the results indicate the effectiveness' of the program increasing the level of knowledge of teachers the principles of behavior modification and tactics, and the results showed the presence of statistically significant differences in performance attributable to the qualified science to a time when it was not for sex and teaching experience any significant effect.

\subsection{Al-Khatib Study, 2004a}

A study entitled the effectiveness of the development of teachers' knowledge modify behavior in reducing behavior stereotyping and aggressive and chaotic in a sample of children with mental disabilities in Jordan, the aim of this study was to evaluate the effectiveness of a training program behavioral multi-component in reducing aggressive behavior, chaotic, and stereotyping in children with mental disabilities, and included in the study (81) distributors child randomly into two groups, controller, experimental and pointed to the existence of output statistically significant differences between the children in the experimental group and the children in the control group with respect to each of aggressive behavior, and chaotic, typical.

\subsection{Al-Khatib also Held A Study, $2004 b$}

A study entitled the effectiveness of a training program in the development of knowledge of teachers of mentally disabled children the principle of behavior modification and tactics, aimed to assess the effectiveness of a training program behavior in the development of the level of teacher' knowledge in ways that behavior modification for disabled children include the study sample (28) teachers were selected in a manner deliberate study found that there statically significant differences between teachers in the experimental group. 


\subsection{Al-Khatib also Held A Study, 1993}

Aimed to know the teachers of mentally disabled in ways that behavior modification and specifically whether that knowledge is depending on teaching experience and qualification, and included a sample (74) teachers working with children with mental disabilities, end the study found that the level of the teachers' knowledge of those principles did not reach the level required on any part of the test as a whole, the results also showed no significant differences in the level of knowledge that is attributable to any of the teaching experience or academic qualification.

\subsection{Al-Tal study 1981}

Aimed to identify the core competence to be met with teachers of kids with disabilities to deal with these kids well, where one part of study was the efficiencies of behavior modification, and included a sample of (170) teachers in special education centers in the city of Amman and the results indicated the presence of statistically significant differences for the benefit of the parameters with respect to the existence of efficiencies of behavior modification. Through a reviews of previous studies two studies are remarkable, first (Dizdorn, 2000) and secondly (Abed \& Abu-Hawash, 2011), dealt with counselors knowledge of strategies to modify the behavior directly, while the rest of the studies dealt with the effectiveness of programs, behavior modification or talked about the competencies and skills of teachers and therefore the current study differs from its predecessors as measure the extent of knowledge of counselors strategies for behavior modification using a scale that was developed for this purpose, and knowledge of the impact of some of the variables on that knowledge. The current study benefited from previous studies in (the preparation of the theoretical framework, a tool of the study, discuss the results).

\section{Problem of the Study}

The researcher noticed through its expertise in the field of guidance that counselors vary in degree of their knowledge of strategies to modify the behavior, which affects the effectiveness of extension services provided, and the relationship between guidance and guided, but due to lack of available knowledge of scientific and objective information on the side of researcher about the level of knowledge do the counselors of Balqae Governorate have on behavior modification strategies and how to deal with them. This study was to show the level of knowledge of these guides for these strategies and specifically this study tried to answer the following two questions:

- What degree of knowledge of counselors to behavior modification strategies in Balqa Governorte.

- Do vary the degree of knowledge of the behavior modification strategies of counselors in different variables (sex, years of service)?

\section{The Importance of the Study}

The importance of the study lies in the important of the subject matter covered both theoretical and practical as important theory, the counselors knowledge of strategies for behavior modification has a great role to do their job, which affect the effectiveness of the services provided to the guided and the relationship between them, either in practice it is hoped that the benefit to this study following entities:

1) Educational counselors, because obtaining feedback regarding the level of knowledge of behavior modification strategies, stimulate them to modify their strategies in dealing with guided become more motivated and productive work and more commitment to their duties.

2) Officials at the Ministry of Education, and private planners for training programs for the preparation of mentors, if that inform them of the results of this study may be useful to them in order to include training programs topics related strategies behavior modification, which will lead to the upgrading of the profession of counseling and then to improve services for guided and developed.

3) Researchers in the field of educational and psychological counseling, this study opens the door to other studies from which to take behavior modification strategies of other aspects are complementary to the current topic.

\section{The Limits of the Study}

\subsection{Human Limits}

The study was limited to a sample of counselors in public schools of the Education Directorates in Balqa Governorate, and thus it cannot be circulated its results except the samples have the same characteristics of the sample had been studied. 


\subsection{Temporal Boundaries}

This study was conducted in the first semester of the academic year 2012 - 2013.

\section{Terms of the Study}

\subsection{School Counselor}

A person who acts in an educational and behavioral counseling, and holds a scientific degree in the fields of psychological counseling and psychology, and works in schools in the Ministry of Education in Jordan to provide extension services.

\subsection{The Knowledge of the Methods of Behavior Modification}

In this study it is represented by the total score obtained by the guides on the knowledge test scale of behavior modification strategies.

\subsection{Behavior Modification Strategies}

The knowledge of counselors to the principles of behavior modification, methods to strengthen appropriate behavior, methods of shaping behavior and methods of reducing inappropriate behavior.

\section{Method and Procedures}

\subsection{Methodology}

The researcher followed in this study the analytical descriptive method to measure the extent of counselors 'knowledge of behavior modification skills in the Balqa governorate, where she has distributed the tool to obtain the required information in the study.

\subsection{The Studying Society}

The current study population consisted of all counselors who work in regular and private schools in the Balqa governorate for the academic year 2012-2013.

\subsection{The Studying Sample}

This study was conducted on a sample of counselors which consisted of (80) mentors, who were selected randomly from among all workers enrolled in regular public school and private in the Balqa governorate. It has been taken into account the selection of the sample represents to variables of the study, which were represented, race, years of experience, and Table 1 shows that

Table 1. shows the distribution of the sample

\begin{tabular}{llll}
\hline Total & number & variable levels & Variable \\
\hline 80 & 30 & Male & Sex \\
& 50 & female & \\
80 & 35 & less than ten years & Experience \\
& 45 & more than ten years & \\
\hline
\end{tabular}

\subsection{The study variables}

The study includes the following changes:

- Independent variables which included:

a - It has two levels of sex (male) and (female)

$\mathrm{b}$ - The educational experience has two levels (less than ten years) (over ten years).

- The dependent variable is the counselors' level knowledge to the behavior modification strategies.

\subsection{The Study Tool}

To study the counselor level knowledge in behavior of modification strategies in Balqa governorate, the researcher prepared a standard scale by reference to the scale prepared by (Abed, Abu Hawash, 2011) to measure the skills of behavior modification, where the scale consisted of two parts:

Part I: General data relating to members of the sample in terms of sex and years of experience. 
Part II: a scale consists of (48) multiple-choice items distributed between the principles of behavior modification strategies, strengthening behavior strategies, the formation of behavior strategies, behavior reduction strategies.

\subsection{Honest Tool}

It has been verified from the veracity of the tool by showing it to a number of specialists arbitrators in private education, measurement, evaluation, a number of specialists in educational technology, and guidance in Jordanian universities, so as to arbitrate it in terms of the language and make it suitable for measuring the degree of counselors' knowledge of behavior modification strategies, and in the light of the views of the arbitrators and their suggestions some of the paragraphs amended and new paragraphs added and these measures were considered sufficient to right scale.

\subsection{The Stability of the Tool}

Stability has been verified by application of the scale tool on an exploratory sample of (30) male and female mentors from outside the study sample where Reliability coefficient was extracted using Cranach's alpha and the degree of knowledge for behavior modification strategies was (0.94)

\subsection{Correction Scale}

It has been using Likert quintet scale (very large, large, medium, small, and very small). Estimates were give following digital $(1,2,3,4,5)$ estimating the degree of counselors' knowledge in behavior modification strategies and it has been used the following gradient:

$$
\begin{array}{ll}
1-1.79^{\circ} & \text { very few } \\
2-1.8-2.59 & \text { Low degree } \\
3-2.6-3.39 & \text { Medium degree } \\
4-3.4-4.19 & \text { large degree } \\
5-4.2-5 & \text { very large degree }
\end{array}
$$

\subsection{The Study Measures}

* Identify the problem of the study and its questions.

* Building study tool by reviewing the educational literature and previous studies due to relationship.

* Make sure the sincerity and tool persistence.

* Identify the studying society and its sample.

Distribution of study tool by hand to all members of study sample and providing them with any clarification in the first semester.

\subsection{Statistical Processing}

Averages, standard deviations and arrangement of each paragraph of the measure were extracted as well as the use of ( $T$ ) test to examine the differences between the study variables.

\section{Results of the Study and Discussion}

\subsection{The Results of the First Question}

How is the counselors' level knowledge in Balqa governorate for behavior modification strategies?

To answer the question, the researcher extracted the averages and standard deviations of the level of counselors' knowledge of behavior modification strategies are shown in Table No. (2) (average and standard deviations for each paragraph of the scale ) 
Table 2. Averages and standard deviations for the paragraphs of the counselors' level knowledge in behavior modification strategies for each paragraph in the tool arranged by arithmetic averages

\begin{tabular}{|c|c|c|c|c|c|}
\hline Ranking & $\begin{array}{l}\text { Degree } \\
\text { possession }\end{array}$ & $\begin{array}{l}\text { Standard } \\
\text { Deviation }\end{array}$ & Average & Paragraph & Number \\
\hline 4 & very large & 0.67 & 4.41 & $\begin{array}{l}\text { The child acts during the lesson in self-harm } \\
\text { behavior, the best way to modify this behavior } \\
\text { of the child is }\end{array}$ & 1 \\
\hline 11 & Large & 0.85 & 3.96 & $\begin{array}{l}\text { The training of the child on the skill of brushing } \\
\text { teeth, start to open a toothpaste tube, and put a } \\
\text { small amount of toothpaste on the brush ... is an } \\
\text { example of }\end{array}$ & 2 \\
\hline 2 & very large & 0.71 & 4.54 & $\begin{array}{l}\text { task analysis is one of the techniques used in } \\
\text { behavior modification, which means }\end{array}$ & 3 \\
\hline 15 & Large & 0.81 & 3.78 & $\begin{array}{l}\text { A concealment is one of the methods used to } \\
\text { modify the behavior, which means }\end{array}$ & 4 \\
\hline 29 & Large & 1.12 & 3.13 & Reinforcement is known as ....... & 5 \\
\hline 8 & very large & 0.97 & 4.28 & The behavior in behavioral point of view is & 6 \\
\hline 18 & Large & 0.68 & 3.65 & Amortization is defined as & 7 \\
\hline 36 & Medium & 0.89 & 2.89 & An example of verbal indoctrination & 8 \\
\hline 10 & Large & 0.68 & 3.99 & $\begin{array}{l}\text { the rules called by which the regulation of } \\
\text { relations between behavior and reinforcement } \\
\text { are ....... }\end{array}$ & 9 \\
\hline 7 & very large & 0.68 & 4.29 & $\begin{array}{l}\text { method of indoctrination and configuration are } \\
\text { among the methods used in }\end{array}$ & 10 \\
\hline 40 & Small & 0.00 & 1 & $\begin{array}{l}\text { sequencing method is used to analyze the task to } \\
\text { teach the child new behavior and the first step } \\
\text { starts out is }\end{array}$ & 11 \\
\hline 4 & Large & 1.09 & 4.41 & $\begin{array}{l}\text { a child who has difficulty in writing neatly and } \\
\text { clearly is a child has }\end{array}$ & 12 \\
\hline 1 & very large & 0.69 & 4.56 & indoctrination is defined as & 13 \\
\hline 39 & Small & 0.79 & 1.39 & $\begin{array}{l}\text { Modeling is one of the adopted methods in } \\
\text { behavior modification and means }\end{array}$ & 14 \\
\hline 17 & Large & 0.84 & 3.71 & $\begin{array}{l}\text { The first step in the process of behavior } \\
\text { modification is }\end{array}$ & 15 \\
\hline 4 & very large & 0.69 & 4.44 & $\begin{array}{l}\text { factors that increase the effectiveness of the } \\
\text { reinforcement }\end{array}$ & 16 \\
\hline 28 & Large & 0.84 & 3.26 & $\begin{array}{l}\text { The child's behavior aggressively in the } \\
\text { presence of the mother and his } \\
\text { non-aggressive behavior in presence of the } \\
\text { father is an example of the principle of }\end{array}$ & 17 \\
\hline 28 & Large & 0.69 & 3.26 & punishment is defined as & 18 \\
\hline 21 & Large & 0.87 & 3.58 & $\begin{array}{l}\text { examples of indoctrination with body } \\
\text { guidance }\end{array}$ & 19 \\
\hline 4 & very large & 0.71 & 4.41 & $\begin{array}{l}\text { removing the child from the enhanced } \\
\text { environment and put him in a special } \\
\text { environment is enhanced when he is in } \\
\text { undesirable behavior }\end{array}$ & 20 \\
\hline 9 & very large & 0.58 & 4.09 & $\begin{array}{l}\text { The teacher (Khalid) reinforced the student } \\
\text { (Ahmed) once an hour later, and again after } 3\end{array}$ & 21 \\
\hline
\end{tabular}




\begin{tabular}{|c|c|c|c|c|c|}
\hline & & & & $\begin{array}{l}\text { hours, and a third time after two hours, this } \\
\text { procedure is an example of }\end{array}$ & \\
\hline 15 & Large & 0.81 & 3.78 & $\begin{array}{l}\text { the formed behavior from the menders of } \\
\text { behavior point of view is }\end{array}$ & 22 \\
\hline 31 & Large & 1.20 & 3.01 & $\begin{array}{l}\text { the following less reinforcement fire-resistant } \\
\text { schedules are }\end{array}$ & 23 \\
\hline 19 & Large & 0.98 & 3.65 & $\begin{array}{l}\text { The loss of the enhanced value of primitives } \\
\text { known as }\end{array}$ & 24 \\
\hline 32 & Large & 1.17 & 2.99 & $\begin{array}{l}\text { The teacher often gets chaotic student out from } \\
\text { grade ... What the teacher does for this student is }\end{array}$ & 25 \\
\hline 27 & Large & 0.98 & 3.33 & $\begin{array}{l}\text { neutral stimulus who becomes an impact on } \\
\text { behavior by the experience and pairing called }\end{array}$ & 26 \\
\hline 35 & Medium & 1.13 & 2.90 & $\begin{array}{l}\text { configuration is one of the behavior } \\
\text { modification axes which means }\end{array}$ & 27 \\
\hline 22 & Large & 0.98 & 3.56 & $\begin{array}{l}\text { When the teacher displays a list containing a } \\
\text { group of reinforces on the student, the teacher } \\
\text { aims behind it to }\end{array}$ & 28 \\
\hline 25 & Large & 0.86 & 3.35 & $\begin{array}{l}\text { to force an individual who abused disposition to } \\
\text { bear the results of his behavior by removing the } \\
\text { damage that has resulted in ... This method is }\end{array}$ & 29 \\
\hline 6 & very large & 1.09 & 4.31 & $\begin{array}{l}\text { to force a person to perform inappropriate } \\
\text { behavior repeatedly for a specified period of } \\
\text { time in order to link the inappropriate behavior } \\
\text { with tiredness }, \ldots \text { This strategy }\end{array}$ & 30 \\
\hline 15 & Large & 0.81 & 3.78 & $\begin{array}{l}\text { rein forcers that can be replaced later with other } \\
\text { ones are }\end{array}$ & 31 \\
\hline 29 & Large & 1.12 & 3.13 & $\begin{array}{l}\text { The principle which constitutes the cornerstone } \\
\text { in the field of behavior modification is }\end{array}$ & 32 \\
\hline 26 & Large & 1.16 & 3.34 & $\begin{array}{l}\text { when strengthen the response leads to the } \\
\text { increase in the possibility of occurring of similar } \\
\text { responses in the future, what happened is called: }\end{array}$ & 33 \\
\hline 16 & Large & 0.80 & 3.73 & $\begin{array}{l}\text { When using negative reinforcement, this } \\
\text { includes }\end{array}$ & 34 \\
\hline 12 & Large & 0.58 & 3.91 & $\begin{array}{l}\text { The difference between procedural behavior and } \\
\text { responsible behavior }\end{array}$ & 35 \\
\hline 14 & Large & 0.87 & 3.85 & $\begin{array}{l}\text { one of the most important methods used to } \\
\text { increase the effectiveness of formation }\end{array}$ & 36 \\
\hline 38 & Medium & 0.50 & 2.54 & the sequence has two types & 37 \\
\hline 37 & Medium & 0.62 & 2.73 & $\begin{array}{l}\text { strengthening the absence of behavior is known } \\
\text { that }\end{array}$ & 38 \\
\hline 34 & Medium & 0.82 & 2.94 & $\begin{array}{l}\text { having been trained child on greeting to his } \\
\text { partners became greeting to his relatives, this is } \\
\text { called }\end{array}$ & 39 \\
\hline 20 & Large & 0.97 & 3.63 & $\begin{array}{l}\text { stimuli that are rewarded or punished behavior } \\
\text { of their existence called stimuli }\end{array}$ & 40 \\
\hline
\end{tabular}




\begin{tabular}{|c|c|c|c|c|c|}
\hline 24 & Large & 1.08 & 3.36 & $\begin{array}{l}\text { stimulus that weakens the possibilities of } \\
\text { procedural behavior if the behavior happened } \\
\text { before }\end{array}$ & 41 \\
\hline 33 & Large & 1.04 & 2.98 & $\begin{array}{l}\text { weakening behavior through the elimination of } \\
\text { rein forcers that maintain its continuity called }\end{array}$ & 42 \\
\hline 30 & Large & 1.09 & 3.11 & $\begin{array}{l}\text { The child acts during the lesson in self-harm } \\
\text { behavior, the best way to modify this behavior } \\
\text { of the child is }\end{array}$ & 43 \\
\hline 23 & Large & 1.10 & 3.39 & $\begin{array}{l}\text { Samer abide by the morning in the presence of } \\
\text { the queue in order to avoid Director's } \\
\text { punishment. Samer's behavior here submits to }\end{array}$ & 44 \\
\hline 10 & very large & .0 .82 & 3.99 & $\begin{array}{l}\text { when the target of therapeutic intervention } \\
\text { teaching new behaviors, the appropriate action } \\
\text { would be }\end{array}$ & 45 \\
\hline 5 & very large & 0.95 & 4.34 & $\begin{array}{l}\text { one of the following punitive measures doesn't } \\
\text { include the direct punishment }\end{array}$ & 46 \\
\hline 13 & Large & 0.82 & 3.86 & $\begin{array}{l}\text { When the goal of behavior modification is the } \\
\text { education of the individual series of procedures, } \\
\text { the best procedure is }\end{array}$ & 47 \\
\hline 18 & Large & 1.19 & 3.68 & to remove the gradual indoctrination called & 48 \\
\hline
\end{tabular}

Table 2 shows that the degree of counselors' knowledge to behavior modification strategies were great, as the arithmetic average of the total degree of knowledge of the behavior modification strategies (3.54) with a standard deviation (0.53)

Table 2 shows that (13) paragraphs out of (48) were very much by $23 \%$ and came (30) paragraph out of (48) very great and by $62 \%$ and came (5) paragraphs out of (48) with medium degree by $10 \%$ came paragraphs and (2) paragraphs with small degree by $0.05 \%$.

The researcher explains this result that counselors are available to have information about the nature of the guided and stages of their development, the problems they face and theories that explain the behavior. They are also able to keep up with scientific development and to acquire a weapon of science and knowledge and be able to help the guided, and correction cognitive and behavioral mistakes and improvement their feelings and adopting positive values. The researcher also attributed this result to the efforts of the Ministry of Education for the preparation and rehabilitation of counselors and increasing their awareness of behavior modification strategies . This result is consistent with the findings of the (Dizdron, 2009) and differs with the findings of the (Abed and Abu Hawash 2011).

\subsection{Second Question}

Does the counselors' knowledge of behavior modification strategies depending on sex?

Table 3. Test results ( $\mathrm{T}$ ) the impact of sex in the degree possession of educational technology competencies

\begin{tabular}{llllll}
\hline $\begin{array}{l}\text { The level of } \\
\text { significance }\end{array}$ & $\begin{array}{l}\text { The calculated } \\
\text { value of } \mathrm{T} \text {. }\end{array}$ & Standard deviation & Average & Number & Sex \\
\hline 0.852 & 0.19 & 0.77 & 3.56 & 30 & Males \\
& & 0.32 & 3.54 & 50 & Females \\
\hline
\end{tabular}

Notes from Table 3

There is a lack of statistically significant differences in the degree of counselors' knowledge of behavior modification strategies attributed to sex as the value of $\mathrm{T}(0.19)$ which is not statistically significant. 
The researcher attributed that the males and females councilors are equal in their knowledge of strategies for behavior modification because both parties are being exposed to the same work conditions, especially that they were working in the same ministry: In addition to the quality of rehabilitation received by the counselor whether male or female, where similar in terms of curriculum, methods of practical application and theoretical. This result is also consistent with the results of a Khatib study (2005), Abed Abu Hawash (2010).

\subsection{The Third Question}

Does the counselors' knowledge of behavior modification strategies depending on experience in counseling?

Table 4. Test results $(\mathrm{T})$ the impact of experience in the degree possession of educational technological competencies

\begin{tabular}{llllll}
\hline $\begin{array}{l}\text { The level of } \\
\text { significance }\end{array}$ & $\begin{array}{l}\text { The calculated } \\
\text { value of T }\end{array}$ & $\begin{array}{l}\text { Standard } \\
\text { deviation }\end{array}$ & Average & Number & $\begin{array}{l}\text { Years of } \\
\text { experience }\end{array}$ \\
\hline 0 & 4.46 & 0.50 & 3.27 & 35 & $\begin{array}{l}\text { less than ten } \\
\text { years } \\
\text { more than } \\
\text { ten years }\end{array}$ \\
\hline
\end{tabular}

It is shown in Table 4 that the presence of statistically significant differences between the estimates average members of the study sample with long experience in counseling (over ten years) and estimates average members of the sample who are experienced (less than ten years ) in benefit of that group with long experience in counseling .

The researcher explains this result on the basis that counselors are had an experience of ten years or more have joined training courses more than those who have been working in guidance less than ten years and this in turn has led to increase efficiencies for them. This result has also attributed to the educational experience for the counselors' have given them an ability to deal with such problems, and choose the appropriate methods for treating it. In addition to the experience which leads to gain renewable skills, and develop gained skills making the counselor more enthusiastic and more experienced where his level of knowledge of strategies for behavior modification rises and thus this result agreed with the findings of Sa'da and his colleagues (1982), Abed (2010) and disagreed with what reached Khatib (2005).

\section{Recommendations}

The researcher recommends in light of the results that study, including the following:

1) Enrich preparation programs for the counselors' in universities with more courses in the field of behavior modification.

2) Holding training courses for counselors during the service based on the awareness of behavior modification strategies and their practical applications.

3) Conduct studies covering aspects that are not covered by the current study.

4) Providing printed materials in the form of brochures or booklets and periodically for the counselors about the applications of behavior modification and what is new in behavioral therapy.

\section{References}

Abu Humaydan, Joseph. (2003). Behavior modification theory and practice. Term Publishing and Distribution: Amman, Jordan.

Alberto, P., \& Troutman, A. (2000). Applied behavior analysis for teachers. Columbus, Ohio: Charles E. Merrill.

Arabi, \& Wadah Mamdouh. (2007). knowledge of autistic children in the Syrian Arab Republic, Behavior modification techniques: Unpublished Master Thesis (University of Jordan), Amman.

Cautilli, J. D., \& Dziewolska, H. (2008). Licensing behavior analysis. International Journal of Behavioral Consultation and Therapy, 4(1), 1-13. 
Dizdron. (2009). Know the extent of use of extension educators in regular schools in Ireland, programs and plans based on modified Alsok and find out the effectiveness of these programs. Education and Treatment of Children, 23, 55-64.

Gelso, C. J., \& Samstag, L. W. (2008). A tripartite model of the therapeutic relationship. In S. Brown, \& R. Lent (Eds.), Handbook of Counseling Psychology (4th ed. pp. 267-283). NY: Wiley.

Hill, Hope. (1981). core competencies necessary for teachers with disabilities. Unpublished Master Thesis (University of Jordan): Amman - Jordan.

Hursh, D., Schumaker, J., Fawcett, S., \& Sherman, J. (2000). A comparison of the effects of written versus direct instructions on the application of four behavior change processes. Education and Treatment of Children, 23, 455-464.

Khatib, Jamal. (1993). level of knowledge teachers of mentally retarded children behavior modification techniques. Journal of Studies, 20(1), 338-355.

Khatib, Jamal. (2003). Modulation of human behavior / manual workers in the fields of psychological, educational and social development. I 1, craving for Publishing and Distribution, Amman, Jordan.

Khatib, Jamal. (2005). the effectiveness of collective training program to improve the level of knowledge teachers of mentally disabled children with behavior modification skills. Journal of the Association of Arab Universities Educational Psychology, 2, 101-116.

Khatib, Jamal. (2006). the level of knowledge regular classroom teachers to learning difficulties and after The training program is developed based on convictions teaching to these teachers. International ConferenceonLearningDisabilities:Riyadh,SaudiArabia.

Khatib, Jamal. (2004a). the effectiveness of the development of teachers' knowledge modify behavior in reducing stereotyping and aggressive behavior and disorderly in a sample of mentally disabled children in Jordan. Journal of Education, 73, 59-90.

Khatib, Jamal. (2004b), the effectiveness of a training program to develop teachers' knowledge of mentally disabled children the principles and methods of behavior modification. Journal of EducationalSciences, 3, 241-261.

Martin, G., \& Pear, J. (2007). Behavior modification: What it is and how to do it (8th Ed.). Upper Saddle River, NJ: Pearson Prentice Hall.

Shang, D. (2008). Know the extent to which school administrators and teachers in ordinary Indonesia on how to deal with people with special need. Journal of Applied Behavior Analysis, 42, 51-62.

Sovereign, Louis. (1994). behavioral therapy and behavior modification. I 2: Egyptian Renaissance House, Cairo, Arab Republic of Egypt.

Thorndike, E. L. (1911). "Provisional Laws of Acquired Behavior or Learning". Animal Intelligence, New York: The McMillian Company.

Whaley, C. (2002). Special Education Teachers and Speech Therapist Knowledge of Autism Spectrum Disorder: Unpublished doctoral dissertation, East Tennessee State University.

Whitman, T., Sciback, J., \& Reid, D. (1983). Behavior modification with the severely and profoundly retarded. New York: Academic Press.

\section{Appendix}

Appendix A. Study tool

In the name of God the Merciful, the Passionate

Dear distinguished counselors in Balqa Governorate,

Greetings ..

The tool in your hands is trying to stand up on your knowledge of behavior modification strategies, and its relationship with some variables. Wish you all the cooperation, note that the information will be obtained for scientific purposes only, and will be treated confidentially and scientific secretariat.

Please fill out this information to the extreme importance and placing signal (x) in the right place: 


\section{Gender \\ Male $\quad \square \quad$ Female \\ Teaching Experience \\ 1-10 years $\square \quad$ more than 10 years $\square$}

Please fill out this information to the extreme importance and draw a circle around the correct answer code:

1 ) The first step in the process of behavior modification are:

A - Measure the target behavior $\quad \mathrm{b}$ - the definition of target behavior $\quad \mathrm{c}$ - identifying target behavior

2 ) The training of the child on the skill of brushing your teeth, starting with open a toothpaste tube, and putting a small amount of toothpaste on the brush by pressing tube, then starting with move the brush on the teeth, and so on reaching the final episode; a dry face and hands. is an example:

a - Back sequence b- Side sequence c-Front sequence

3 - The task analysis is one of the techniques used in behavior modification, which means:

a - A detailed description of each sub-behavior is needed to achieve the ultimate objective behavioral.

$\mathrm{b}$ - A general description of each behavior is necessary to achieve the ultimate objective behavioral.

c - Initial description of each sub-behavior necessary to achieve the ultimate objective behavioral.

4- A concealment is one of the methods used to modify the behavior, which means:

a - Removing the indoctrination stimuli gradually after the success in achieving the goal.

$\mathrm{b}$ - Adding the indoctrination stimuli gradually after the success in achieving the goal.

$\mathrm{c}-$ Removing the indoctrination stimuli temporarily after the success in achieving the goal.

5 - Reinforcement is defined as:

a - any procedure that leads to increasing the possibilities of behavior's occurrence in the future.

$\mathrm{b}$ - any procedure that precedes behavior and lead to increasing the possibilities of its occurrence in the future.

$\mathrm{c}$ - any procedure follows the behavior and leads to increasing the possibilities of its occurrence in the future.

6- The behavior in behavioral point of view is:

a-Stimuli. b- Responses. c-Titles.

7- Extinction is defined as:

$a-$ Removing reinforces that maintain the appearance of unwanted behavior.

$\mathrm{b}$ - Adding reinforces that keeps unwanted behavior.

$\mathrm{c}-$ Removing reinforces that maintain the appearance of the desired behavior.

8- An example of verbal indoctrination is:

a - The teacher distributes images showing children the proper way to clean teeth.

b- The father puts his hand on the child's hand to teach him how to hold the pen correctly.

c- The teacher says to children: "I suggest you carry out this activity in small groups"

9- The rules called by which the regulation of relations between behavior and reinforcement are:

a- Forms of reinforcement. b- Types of reinforcement. c- Reinforcement schedules.

10- The method of indoctrination and formation are methods used in:

a - Learning individuals new behaviors which they didn't have.

b- Increasing desired behaviors among individuals.

c- Reducing unwanted behaviors.

11- The sequencing method is used to analyze the task to teach the child new behavior and the first step he begins is:

a - Behavioral goal setting and defining it strictly. $\quad b$ - Reinforcement. c- Indoctrination.

12 - The child who has difficulty in writing neatly and clearly is a child has a problem in:

a- Repeating the behavior. 
b- Period of behavior.

c- Form of behavior.

13- Indoctrination is defined as:

a- Of somatic instructions to increase the likelihood of the child to perform the desired behavior.

b- Use hints, verbal instructions, physical or pantomime to increase the prospects for a child to Perform the desired behavior

c- Use aids of teaching to increase the likelihood of a child to perform the desired behavior

14- Modeling is one of the methods in behavior modification and means:

a - Information receiving during the performance of the required task.

$\mathrm{b}$ - Simulation (imitation) model behavior after explaining the way to perform the desired task.

c - Promote learner behavior.

15- The child's behavior aggressively in the presence of the mother and his behavior non-aggressively in presence of the father is an example of the principle:

$\mathrm{a}-$ Generalization. $\quad \mathrm{b}$ - Discrimination. $\quad \mathrm{c}$-Extinction.

16- One of the factors that increase the effectiveness of reinforcement is :

a-Satiation. b - Immediate reinforcement. c - Postponed reinforcement.

17- Punishment is defined as:

a - Stimulus occurs after the behavior and leads to reduction to its occurrence in the future.

b - Stimulus occurs before the behavior and leads to reduction to its occurrence in the future .

$\mathrm{c}$ - Stimulus occurs after the behavior and leads to increasing in its occurrence in the future.

18- A child does a self-harm behavior during the lesson, the best way to modify the behavior of this child is:

a- Exclusion. b- Ignore. c - Differential reinforcement to a gradual decrease.

19- One of the examples of indoctrination with physical guidance is:

a - The mother holds her child's hand to help him down or up the stairs.

$\mathrm{b}$ - The teacher says to the children: "I suggest you acting this activity in small groups.

$\mathrm{c}$ - The teacher writes steps of problem solving on paper and distributed it between children.

20- The procedure, which summarized in removing the child from the enhanced environment and put him in a special unenhanced environment when doing undesirable behavior, is defined :

21- The teacher (Khalid) promoted student (Ahmed) once an hour later, and again after three hours, and a third time after two hours, this procedure is an example of:

$\mathrm{a}$ - Table strengthen the fixed period $\mathrm{b}$ - Table enhance the changed period $\mathrm{c}$ - Table strengthen the Changing ratio.

22- The various behavior from the behavior modifiers' point of view is:

a - A product of genetic factors. $\quad$ b - The result of an error in the learning process. $\quad c$ - The product of internal psychological conflicts.

23- The least existence -resistant reinforcement schedules is:

$\mathrm{a}$ - changing the ratio $\quad \mathrm{b}$ - fixed period $\quad \mathrm{c}$-continued

24- The loss of booster for its enhanced value is known as:

a-Immediate. b- Existence. c- Saturation.

25- The teacher often gets the chaotic student out from class hoping to stop his disorderly behavior, and this procedure is repeated by the teacher with the same student whose chaotic behavior increased, what the teacher is doing for this student is:

$\mathrm{a}$ - Punishment from the second division. $\mathrm{b}$ - Positive reinforcement. $\mathrm{c}$ - Negative reinforcement.

26- The neutral stimulus which has an impact on behavior because of the experience and the pairing is called: 
$\mathrm{a}$-Unconditional stimulus. $\quad \mathrm{b}$-Conditional stimulus. $\quad \mathrm{c}$-Preliminary stimulus.

27- The formation is one behavior modification's axes which means:

a- Promotion of the progressive approach (sequential) of the targeted behavior.

b- Promotion of the progressive approach (sequential) from the initial behavior.

c - Promotion of the progressive approach (sequential) of withdrawal behavior.

28- When the teacher displays a list containing a group of boosters on the student, the teacher aims behind it to:

a - Selection of appropriate reinforces for student.

$\mathrm{b}$ - Strengthening his student on all acceptable behaviors.

c -Taking into account the conditions of use of reinforcement.

29- Enforcing of the individual who abused disposition to take the results of his behavior by removing the damages that has resulted in, or force him to exercise appropriate forms of behavior in situations where there is inappropriate behavior habitually ... This method is the following:

a - Correction excess of - Enhance contrast c behavior - negative practice.

30- Enforcing a person to perform inappropriate behavior repeatedly for a specified period of time to join inappropriate behavior with tiredness, and thus stop him. Examples include giving the child who has a habit of ripping his clothes set of old clothes worn, and force him to shred all, this strategy is known as:

a - Correction excess. $\quad$ b - Enhance contrast. $\quad c$ - Behavior - negative practice.

31- Reinforces that can be replaced in other reinforcements later are :

a - Symbolism. b-Secondary. c - Natural.

32- The principle which constitutes the cornerstone in the field of behavior modification is:

$\mathrm{a}$-Reinforcement. $\quad \mathrm{b}$-Punishment. $\quad \mathrm{c}$ - Stimulus adjusting.

33- When strengthening the response leads to increasing the possibility of similar responses in the future, what happened is called:

a- associated behavioral changes. b - Stimulus generalization. c - Transmission of the impact of the training.

34- When you use negative reinforcement, this includes:

a - Add undesirable stimulus. b - Pull desirable stimulus. c c-Pull stippled stimulus.

35- The difference between procedural behavior and responsible behavior:

a - The procedural behavior is motivated by previous stimuli while responsible behavior is controlled by stimuli that followed.

b - Procedural behavior is controlled by stimuli that followed while responsible behavior is motivated by previous stimuli.

c - Procedural behavior does not affect the environment while responsible behavior affect the environment.

36- One of the most important methods used to increase the effectiveness of the formation is:

a - Using following stimuli to facilitate the process of formation.

b - Using discriminatory stimuli to facilitate the process of formation.

c - Using previous stimuli to facilitate the process of formation.

37- The two types of sequence are:

$\mathrm{a}$ - Front and back sequence. b- Primitive and side sequence. $\mathrm{c}$ - Front and side sequence.

38- Reinforcing the absence of behavior is defined as:

a - differential reinforcement of the gradual decrease of the unwanted behavior.

b - differential reinforcement of other behaviors.

c - differential reinforcement for the gradual reduction of unwanted behavior.

39- Having been trained child on greet his partners, he became used to greet relatives, this is called: 
a - Discrimination. $\quad$ b - Respond generalization. $\quad$ c - Stimulus.

40- The stimuli that are rewarded or punished behavior with their existence called stimuli:

a-Reinforcing punitive. $\quad b$-Discriminatory. $\quad c$-Conditional.

41- The stimulus that weakens the possibilities of procedural behavior if it happened before behavior is:

a - Motivational stimulus.

b - Discriminatory negative stimulus.

c - Punitive stimulus.

42- Weakening behavior through the elimination of reinforces that maintain continuity is called:

a - Adjust stimulus. b-Discrimination. c-Generalization.

43- Weakening behavior through the elimination of reinforces that maintain continuity is called:

$\mathrm{a}$ - Erasing. b-Adjust stimulus. c-Discrimination.

44- Samer abides with the presence of the morning queue in order to avoid headmaster's punishment . Samer's behavior here is controlled by:

a - First- degree punishment $\quad b$ - Negative reinforcement c- Second-degree punishment

45-When the target of therapeutic intervention is to teach new behaviors, the appropriate procedure would be:

a- Sequence. $\quad b$-Indoctrination. c - Formation.

46- One of the following punitive measures doesn't include direct punishment:

a- The cost of responding. b- Extinction c- Exclusion.

47- When the goal of behavior modification is to educate the individual a behavioral series, the most appropriate procedure is:

$\mathrm{a}$ - Formation. $\quad \mathrm{b}$ - Sequence. $\quad \mathrm{c}$ - Reduce the gradual sensitivity.

48- The gradual removing of indoctrination is called:

a - Hiding. b- Extinction. c - Automatic recovery.

\section{Copyrights}

Copyright for this article is retained by the author(s), with first publication rights granted to the journal.

This is an open-access article distributed under the terms and conditions of the Creative Commons Attribution license (http://creativecommons.org/licenses/by/3.0/). 